\title{
Analysis of Structure and function by the LysR-Type Transcriptional Regulator CbbR of Nostoc sp. PCC 7120
}

\author{
Hao-Xi Xu ${ }^{1,2,3}$, Shu-Jing Han ${ }^{1}$, Yong-Liang Jiang ${ }^{1}$, Cong-Zhao Zhou ${ }^{1}$ \\ ${ }^{1}$ School of Life Sciences and Hefei National Laboratory for Physical Sciences at the \\ Microscale, University of Science and Technology of China, Hefei, Anhui 230027, People's \\ Republic of China. \\ ${ }^{2}$ Department of Environmental and Chemical Engineering, Anhui Vocational and technical \\ College, Hefei 230011, China. \\ ${ }^{3}$ Corresponding author: Hao-Xi Xu (e-mail: haoxixu@163.com).
}

\section{Acknowledgments}

This work was supported by Natural Science Foundation of Anhui Provincial Education Department (No. KJ2019A0988) and Excellent Young Talents Fund Program of Higher Education Institutions of Anhui Province (No. GXFX2017213) and Excellent Young Talents Fund Program of Higher Education Institutions of Anhui Province (No. GXYQ2019178).

\begin{abstract}
The LysR-type Calvin-Benson-Bassham cycle transcriptional regulator CbbR plays an important role in $\mathrm{CO}_{2}$ fixation in carbon metabolism in nature, which regulates the gene expression of the key enzyme RibisCO in the Calvin-Benson-Bassham (CBB) cycle. In this study, we optimized the conditions for the transformation, expression, and purification of CbbR in the model algae Nostoc sp. PCC 7120, obtained nick-DNA fragments that could tightly bind to CbbR_7120, and finally obtained CbbR protein crystals. These findings provide great assistance for the final crystallization of CbbR to solve the crystal structure of CbbR, and lay the foundation for understanding the mechanism of $\mathrm{CO}_{2}$ fixation in the CBB cycle.
\end{abstract}

KEY WORDS Proteins, Crystals, Optimization 


\section{Introduction}

Carbon metabolism is essential for the vital activities of various organisms. Organisms can adapt to different growth environments by delicately regulating the balance of carbon metabolism ${ }^{[1]}$. For most prokaryotes and eukaryotes, $\mathrm{CO}_{2}$ is generally the only source of carbon ${ }^{[2]}$. Cyanobacteria are autotrophic photosynthetic microorganisms that have existed on earth since ancient times and are carbon-metabolism model microorganisms to study $\mathrm{CO}_{2}$ as the carbon source ${ }^{[3]}$. Most cyanobacteria are aquatic organisms. To adapt to a gradually decreasing concentration of $\mathrm{CO}_{2}$, cells have evolved to form a set of $\mathrm{CO}_{2}$ concentration mechanisms (CCMs), which can facilitate the acquisition of inorganic carbon source materials (such as $\mathrm{CO}_{2}$ and $\mathrm{HCO}_{3}^{-}$) in cyanobacteria cells under extremely low $\mathrm{CO}_{2}$ concentrations ${ }^{[4]}$. The inorganic carbon source is fixed by 1,5 -ribulose diphosphate (RuBP) carboxylase/oxygenase (RibisCO) in the carboxysome by the transport system, which increases the $\mathrm{CO}_{2}$ concentration in the active center of the enzyme ${ }^{[5][6]}$. In addition, extremely low concentrations of $\mathrm{CO}_{2}$ molecules can also be reduced to carbohydrates in the Calvin-Benson-Bassham (CBB) cycle, thereby greatly improving the efficiency of photosynthesis ${ }^{[7]}$.

The ultimate goal of the $\mathrm{CBB}$ cycle is to fix three molecules of $\mathrm{CO}_{2}$ into one molecule of triose phosphoric acid, that is, the ingested $\mathrm{CO}_{2}$ is reduced into the form of available carbon; therefore, these organisms can synthesize the macromolecular structure substances and energy substances essential for vital activities. In cyanobacteria, the uptake of inorganic carbon sources is greatly regulated at the transcription level. CCM-related genes can be induced by low carbon expression, and these genes are inhibited in high-concentration $\mathrm{CO}_{2}$ environments [8]. The first step of $\mathrm{CO}_{2}$ fixation in the $\mathrm{CBB}$ cycle is the reaction of $\mathrm{CO}_{2}$ with $\mathrm{RuBP}$ into 3-phosphoglycerate (3-PGA) under the catalysis of ribulose-1,5-bisphosphate carboxylase oxygenase (RubisCO). The RibisCO-catalyzed reaction is the main pathway for the fixation of inorganic carbon, which is the key enzyme in the $\mathrm{C} 3$ pathway and is the center of various enzymes in the $\mathrm{CBB}$ cycle. However, due to a lack of high specificity and relatively low catalytic activity, $\mathrm{O}_{2}$ and $\mathrm{CO}_{2}$ will compete for the $\mathrm{CO}_{2}$ binding site in RibisCO under aerobic conditions; thus, $\mathrm{O}_{2}$ becomes linked to the carbohydrate chain to form the incorrect oxidation products ${ }^{[9]}$. Therefore, cells often increase the total amount of fixed inorganic carbon by synthesizing a large amount of RubisCO ${ }^{[10]}$. Moreover, because the assimilation of $\mathrm{CO}_{2}$ has a relatively high energy demand and the burden of additional protein synthesis in cells, the transcriptional regulation of the RubisCo protein gene is of particular significance ${ }^{[11]}$.

The Calvin-Benson-Bassham cycle transcriptional regulator CbbR regulates the gene expression of the key enzyme RibisCO in the CBB cycle ${ }^{[12]}$. The CbbR protein is a type of LysR-type transcriptional regulator (LTTR) ${ }^{[13]}$. CbbR-dependent regulation occurs in different types of organisms, including nonsulfur and purple sulfur bacteria, marine and freshwater chemical autotrophic bacteria, cyanobacteria, methylotrophic bacteria, and 
different pseudomonas, mycobacteria, fusobacterium, etc. Currently, the spatial structure and function of the CbbR homologous proteins $\mathrm{CcmR}{ }^{[14]}$ and $\mathrm{CmpR}{ }^{[15]}$ have been partially resolved. These two transcription factors are both members of the LysR transcription factor family ${ }^{[16]}$. This family of proteins can regulate their own recognition of DNA sequences by binding with effector small molecules during the metabolic process ${ }^{[17]}$. However, the relevant structure and specific regulatory functions of $\mathrm{CbbR}$, which is a key regulatory transcription factor that regulates $\mathrm{CO}_{2}$ fixation, remain unclarified ${ }^{[18]}$. In the present study, we further analyzed the structure and function of $\mathrm{CbbR}$ in future studies by investigating and optimizing the expression, purification, and crystallization conditions of CbbR in model algae.

\section{Materials and methods}

\subsection{Cloning, expression and purification}

The coding region of full-length CbbR was amplified from the genomic DNA of Nostoc sp. PCC 7120 by PCR. The PCR product was cloned into a modified p28 vector with an N-terminal $6 \times$ His-tag (Table 1). The recombinant proteins were overexpressed in Escherichia coli strain Rosetta cells (DE3). Cells were cultured in LB culture medium (5 g of yeast extract, $10 \mathrm{~g}$ of $\mathrm{NaCl}, 10 \mathrm{~g}$ of tryptone per liter, $\mathrm{pH}$ 7) containing $16 \mu \mathrm{g} / \mathrm{mL}$ chloromycetin and $30 \mu \mathrm{g} / \mathrm{mL}$ kanamycin at $37^{\circ} \mathrm{C}$ until the $\mathrm{OD}_{600 \mathrm{~mm}}$ reached 0.8 , and then the cells were induced with $0.2 \mathrm{mM}$ isopropyl- $\beta$-1-thiogalactopyranoside (IPTG) for another $20 \mathrm{~h}$ at $16^{\circ} \mathrm{C}$. The cells were harvested by centrifugation at $8000 \mathrm{~g}$ for $4 \mathrm{~min}$ at $4{ }^{\circ} \mathrm{C}$ and resuspended in loading buffer ( $20 \mathrm{mM}$ Tris, $100 \mathrm{mM} \mathrm{NaCl}, \mathrm{pH} 8.0)$. After sonication for 15 min and centrifugation at $16000 \mathrm{~g}$ for $30 \mathrm{~min}$ at $4{ }^{\circ} \mathrm{C}$, the protein supernatant was loaded onto a nickel-nitrilotriacetic acid (Ni-NTA) column (GE Healthcare) containing $0.1 \mathrm{M} \mathrm{Ni}^{2+}$ and equilibrated with the same loading buffer. The Ni-NTA column was washed with equilibration buffer. The target protein was eluted with loading buffer containing $400 \mathrm{mM}$ imidazole and then purified by gel filtration with a Superdex 200 column on the ÄKTAprime plus system (GE Healthcare) in binding buffer (20 mM Tris-Cl, pH 8.0, $1 \mathrm{M} \mathrm{NaCl}, 2 \mathrm{mM}$ DTT, $0.1 \% \beta-O G)$. The purity of the target protein was confirmed by gel electrophoresis. The fractions containing the target protein were pooled and concentrated using a filter tube to a final concentration of $400 \mathrm{mM}$. 
Table 1. Primer sequence information for the coding region of full-length CbbR from the genomic DNA of Nostoc sp. PCC 7120

5'-CAAAGCGATCGCCCGTGGCTTAGCACCACCACCACCA

Forward primer

\author{
CCACTGA-3'
}

CbbR_7120

5'-GGGTTGTGAAGGCTACTACCGCCCATGGTATATCTCC

Reverse primer

TTCTT-3'

\title{
2.2 Electrophoretic mobility shift assay (EMSA)
}

EMSAs were performed with 5'-FAM-labeled double-stranded oligonucleotides (dsDNA). The complementary single-stranded oligonucleotides were synthesized by General Biosystems (Chuzhou, China) and annealed to produce double-stranded oligonucleotides. A $10 \mathrm{~mL}$ reaction volume containing a 5'-FAM-labeled probe was used with $2.5 \mu \mathrm{L}$ of $5 \mathrm{X}$ binding buffer (100 mM HEPES pH 7.6, 5 mM EDTA, $50 \mathrm{mM}\left(\mathrm{NH}_{4}\right)_{2} \mathrm{SO}_{4}, 5 \mathrm{mM}$ DTT, 1\% Tween 20, and $150 \mathrm{mM} \mathrm{KCl}$ per microliter) and suitable purified recombinant protein. The reaction lasted on ice for $15 \mathrm{~min}$. When required, unlabeled competitors were added to the reaction system for another $15 \mathrm{~min}$ on ice. Then, the reaction solution containing protein-DNA complexes was loaded on $6 \%$ TBE-polyacrylamide gel with $0.5 \%$ TBE loading buffer on ice at $100 \mathrm{~V}$ for $2 \mathrm{~h}$.

\subsection{Crystallization}

The full-length CbbR and protein-DNA complexes were applied for crystallization. Crystals were grown at $289 \mathrm{~K}$ using a Robot preliminary screen (hanging drop method) on 96-well plates with different conditions.

\section{Results and discussion}

\subsection{Molecular sieve purification and electrophoresis verification of CbbR_7120}

The CbbR protein in Nostoc sp. PCC 7120 model algae was selected. The optimal expression conditions (Table 2) were determined by detecting expression, followed by transformation, massive expression, protein purification and detection according to the optimal conditions.

Table 2. The optimal expression conditions of the CbbR protein in Nostoc sp. PCC 7120

\begin{tabular}{|c|c|c|c|c|}
\hline Protein & Competent cells & $\mathrm{T}\left({ }^{\circ} \mathrm{C}\right)$ & Position & $\mathrm{t}(\mathrm{h})$ \\
\hline CbbR 7120 & Rosetta & 16 & Supernatant & 20 \\
\hline
\end{tabular}


bioRxiv preprint doi: https://doi.org/10.1101/2020.08.04 235895; this version posted August 4, 2020. The copyright holder for this preprint (which was not certified by peer review) is the author/funder, who has granted bioRxiv a license to display the preprint in perpetuity. It is made available under aCC-BY 4.0 International license.

(a)

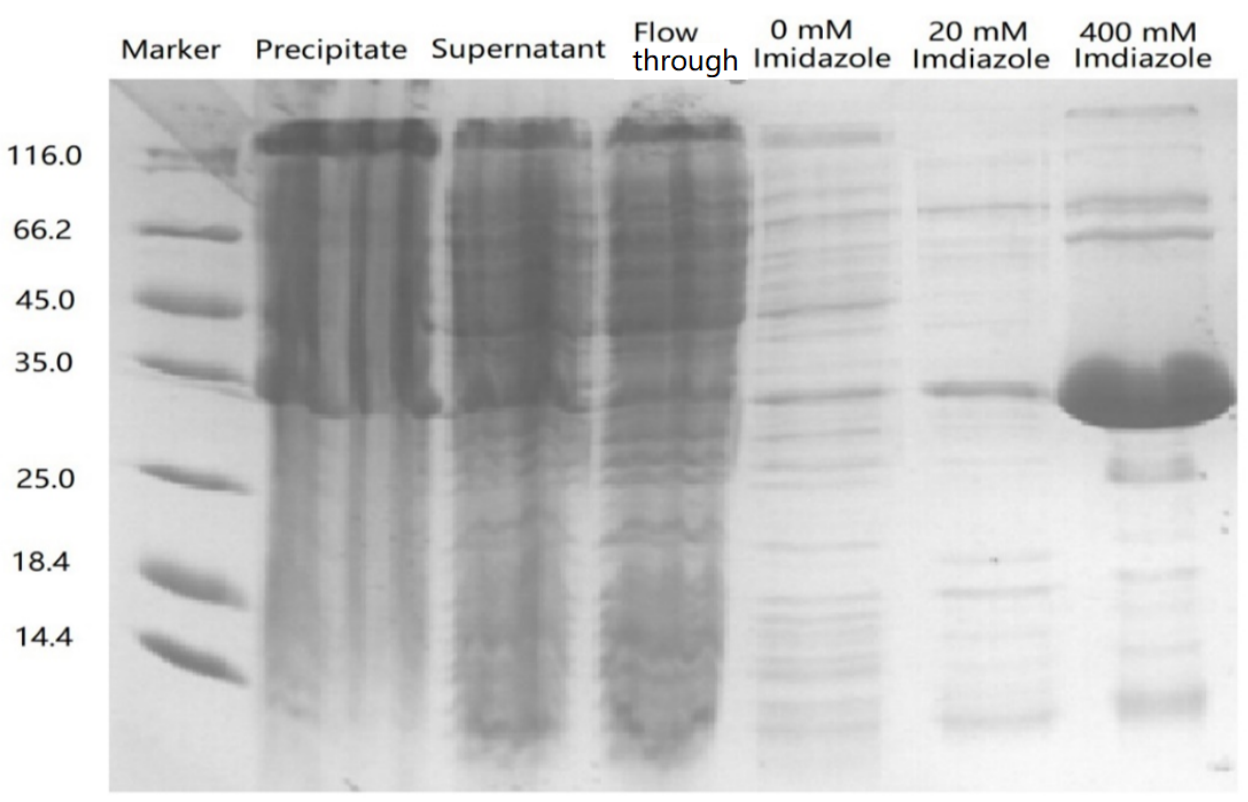

(b)

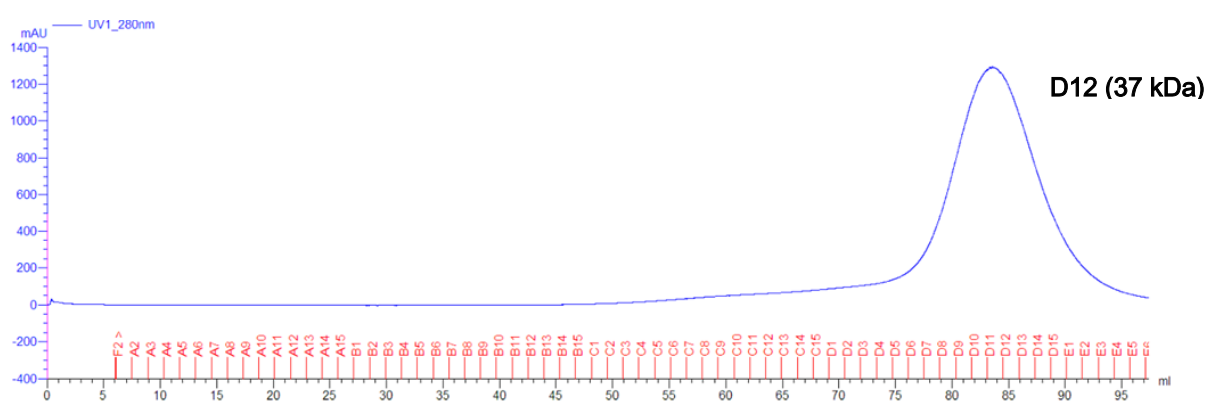

(c)

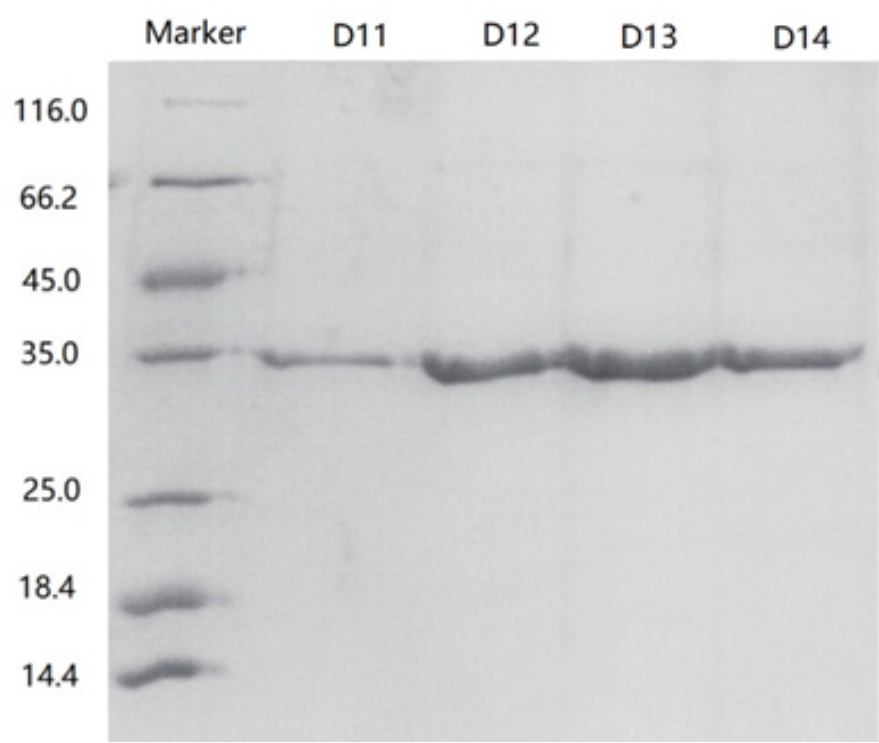

Figure 1. (a) Gel electrophoresis profile of protein fractions from centrifugation. (b) Gel filtration chromatography of the CbbR_7120 protein. (c) SDS-PAGE of the peak fractions from 
gel filtration chromatography.

The protein CbbR_7120 was highly expressed (Fig. 1a). High yield protein bands were present when imidazole was eluted at a concentration of $400 \mathrm{mM}$ but heteroproteins were also present. After purification by molecular sieve chromatography, CbbR_7120 peaked at location D12, and the peak was symmetric and uniform (Fig. 1b). High yield protein bands were present. Peak tip samples were taken for SDS-PAGE to verify protein purity, and we obtained high-purity protein samples (Fig. 1c).

\subsection{Finding nick-DNAs by EMSA}

The DNA sequence of rbcLXS from CbbR_7120 was estimated by the chip-seq method (Fig. 2). The FAM-tagged DNA sequence was designed based on the sequence in Table 3.

$$
\begin{aligned}
& \text { TTTATGTA ATAACA AATTTAAATATGTAAGTTAAGACTTTCAAAGAATAACTTATGCCATTTCTTGATATATI GTG } \\
& \text { AAATACATTATTGT TTAAATTTA TACATTCAATTCT TGAAAGTTTCTTATTGAATACGGTAAAGACTATATAACAC TCTGTTCAATG ITTAAT } \\
& -7 \\
& \text { Box I } \\
& \text { Box II } \\
& \text { Box III }
\end{aligned}
$$

Figure 2. The DNA sequence of the rbcLXS promoter region ${ }^{[19]}$. The transcription initiation point of the operon $(+1)$ and the -10 and -35 boxes are marked in red ${ }^{[20]}$. The three putative binding sites for All3953 (box I, box II and box III) are marked with blue boxes, and the NtcA-binding sites are marked with green boxes.

Table 3. The FAM tagged DNA sequence

Forward strand

5'FAM-TAATAACAAATTTAAATATGTAAGTTAAGAACTTTC

AAAGAATAACTTATGCCATTTCTTGATAT-3'

Reverse strand 


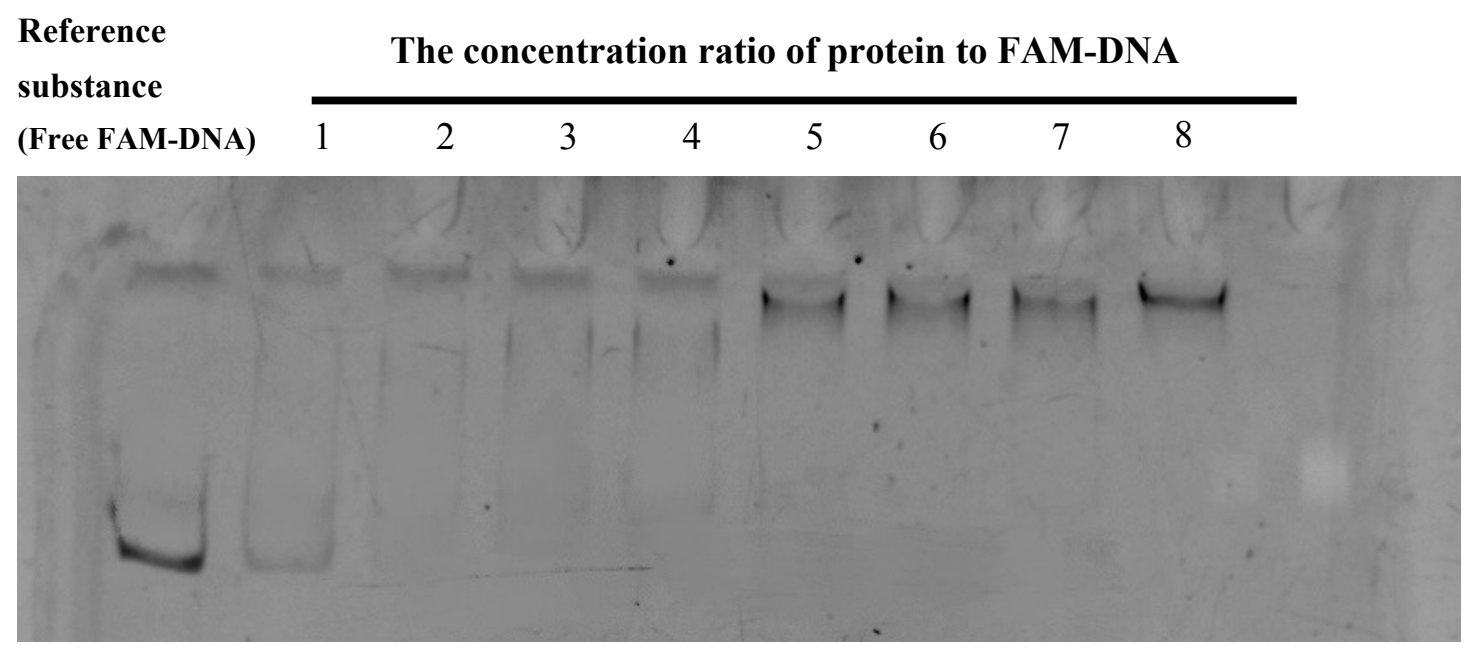

Figure 3. EMSA of the protein CbbR_7120 with different amounts of FAM-DNA for the minimum concentration ratio of protein-DNA-binding.

An amount ratio between protein and DNA equal to or greater than 5 indicates that the DNA and protein are completely bound. The concentration ratio between protein and DNA of 5 was therefore selected in the subsequent assay (Fig. 3).

Nick-DNA fragments (BOX 1, BOX2, BOX3) that could compete with FAM-tagged DNA were designed, including BOX I, BOX II, and BOX III (Table 4); that is, three binding sites that bound to the CbbR_7120 DBD domain. This assay was designed to prove whether the speculated binding sites were correct and to confirm the binding strength of different binding sites with CbbR_7120. The protein-bound FAM-DNA was free under complete competition.

Table 4. The designed competitive nick-DNA primer sequences

\begin{tabular}{lll}
\hline BOX 1 & Forward primer & 5'-TAATAACAAATTTAAATAT-3' \\
& Reverse primer & 5'-ATATTTAAATTTGTTATTA-3' \\
& Forward primer & 5'-AGTTAAGAACTTTCAAAGA-3' \\
BOX 2 & Reverse primer & 5'-TCTTTGAAAGTTCTTAACT-3' \\
& Forward primer & 5'-TTATGCCATTTCTTGATAT-3' \\
BOX 3 & Reverse primer & 5'-ATATCAAGAAATGGCATAA-3' \\
\hline
\end{tabular}


bioRxiv preprint doi: https://doi.org/10.1101/2020.08.04.235895; this version posted Auqust 4, 2020. The copyright holder for this preprint (which was not certified by peer review) is the author/funder, who has granted bioRxiv a license to display the preprint in perpetuity. It is made available under aCC-BY 4.0 International license.

\begin{tabular}{|c|c|c|c|c|c|c|c|c|c|}
\hline $\begin{array}{l}\text { Reference } \\
\text { substance } 1 \\
\text { (Free }\end{array}$ & $\begin{array}{l}\text { Reference } \\
\text { substance } 2 \\
\text { (FAM-DNA }\end{array}$ & \multicolumn{8}{|c|}{$\begin{array}{l}\text { The concentration ratio of } \\
\text { competitive nick-DNA (BOX 1) to FAM-DNA }\end{array}$} \\
\hline FAM-DNA) & $\begin{array}{l}\text {-protein } \\
\text { complexes) }\end{array}$ & 10 & 20 & 40 & 100 & 200 & 400 & 1000 & 2000 \\
\hline
\end{tabular}

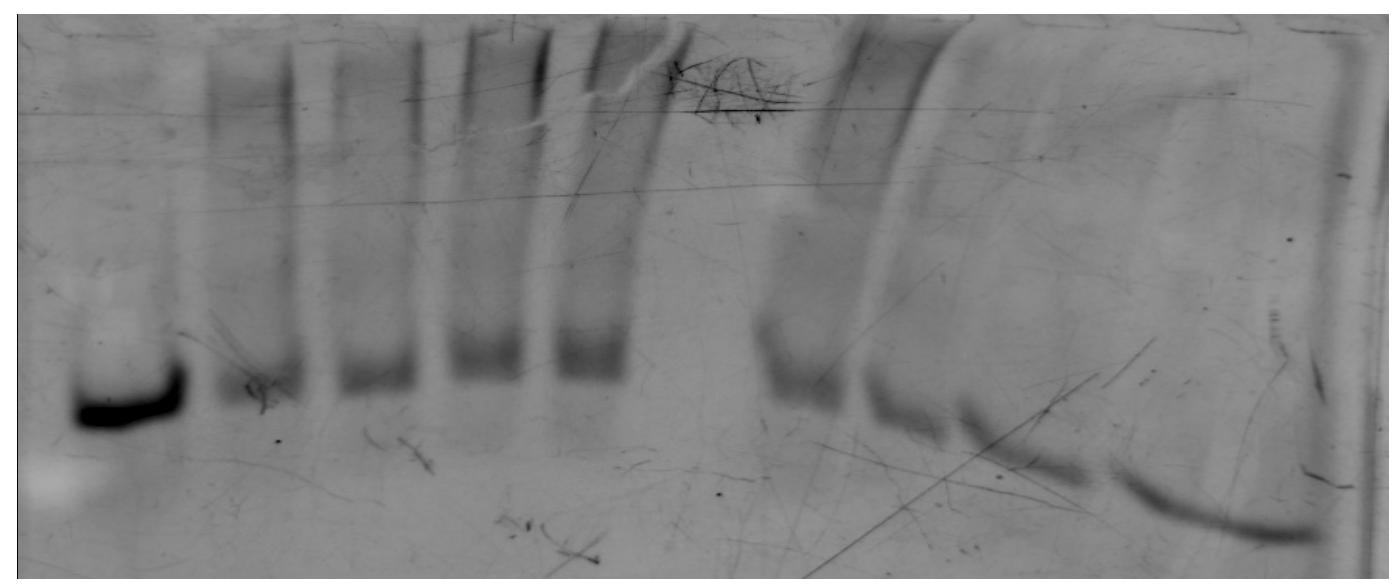

(b)

Reference Reference substance 2

The concentration ratio of

substance 1 (FAM-DNA

competitive nick-DNA (BOX 2) to FAM-DNA

(Free

-protein

FAM-DNA) complexes)

$\begin{array}{llllllll}10 & 20 & 40 & 100 & 200 & 400 & 1000 & 2000\end{array}$

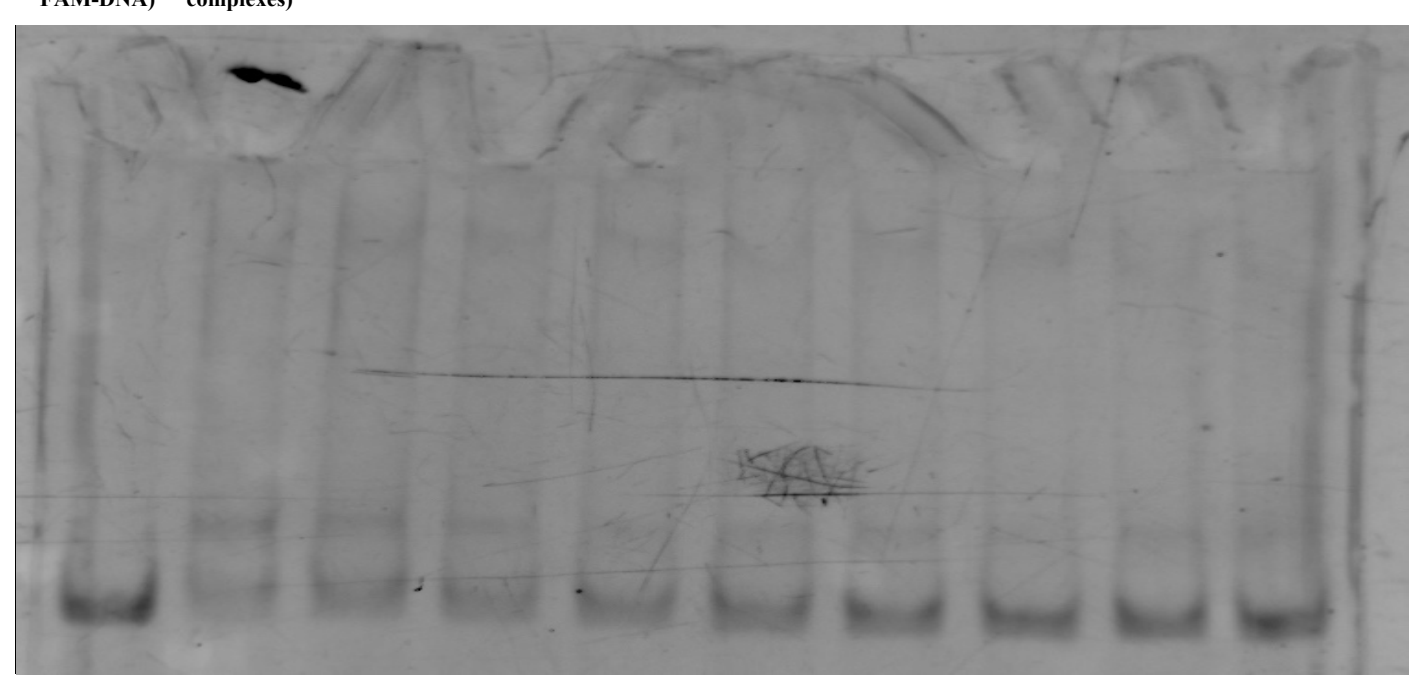




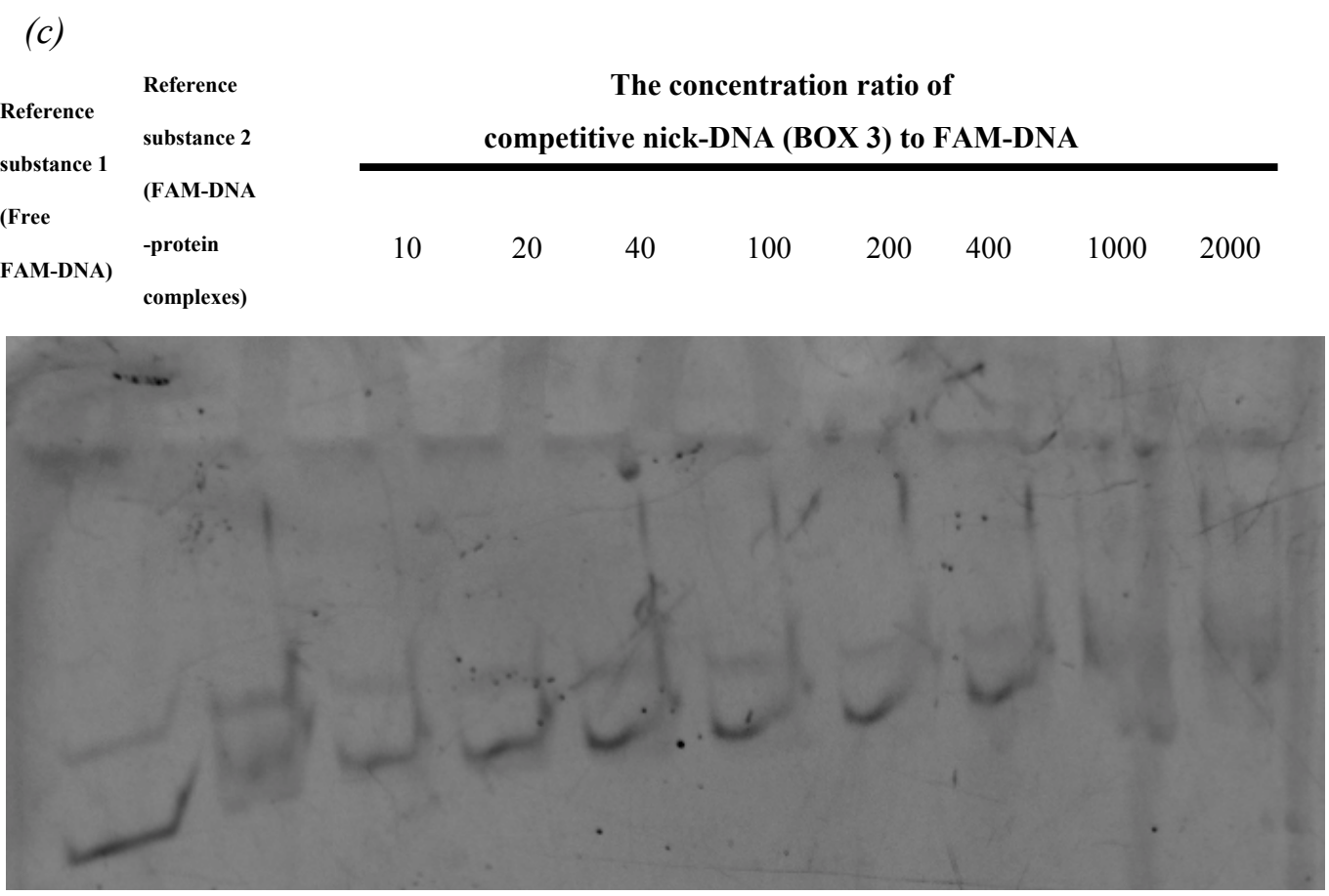

Figure 4. EMSA for detecting the protein binding ability of different competitive nick-DNAs with FAM-DNA.

When competitive nick-DNA (BOX 1) competitively bound to FAM-DNA (Fig. 4a), the concentration of free FAM-DNA fragments gradually increased, while the binding band gradually weakened. The ratio between competitive nick-DNA and FAM-DNA of 400 indicated that the protein-binding FAM-DNA was free and under complete competition.

When competitive nick-DNA (BOX 2) competitively bound to FAM-DNA (Fig. 4b), the concentration of the free FAM-DAN fragment did not significantly change due to competitive binding.

When competitive nick-DNA (BOX 3) competitively bound to FAM-DNA (Fig. 4c), the concentration of free FAM-DNA fragments gradually increased, while the binding band gradually weakened. The ratio between competitive nick-DNA and FAM-DNA of 1000 indicated that the protein-binding FAM-DNA was free and under complete competition.

Finally, it was confirmed that BOX 1 had the strongest binding ability to the CbbR_7120 protein; therefore, the seven nucleotide sequences in the linker region between BOX I and BOX II were optimized, different base-point mutations were designed from these optimal sequences, and the BOX I sequence was repeated and extended appropriately. Four optimal sequences (Box1OP1, Box1OP2, Box1OP3, Box1OP4) were formed (Table 5). Previous experiments have confirmed that the ability of BOX1OP1/BOX1OP3 to compete for binding proteins is relatively strong. Then, the concentration of competitive nick-DNA was decreased for comparison. 
Table 5. Optimized competitive nick-DNA primer sequences

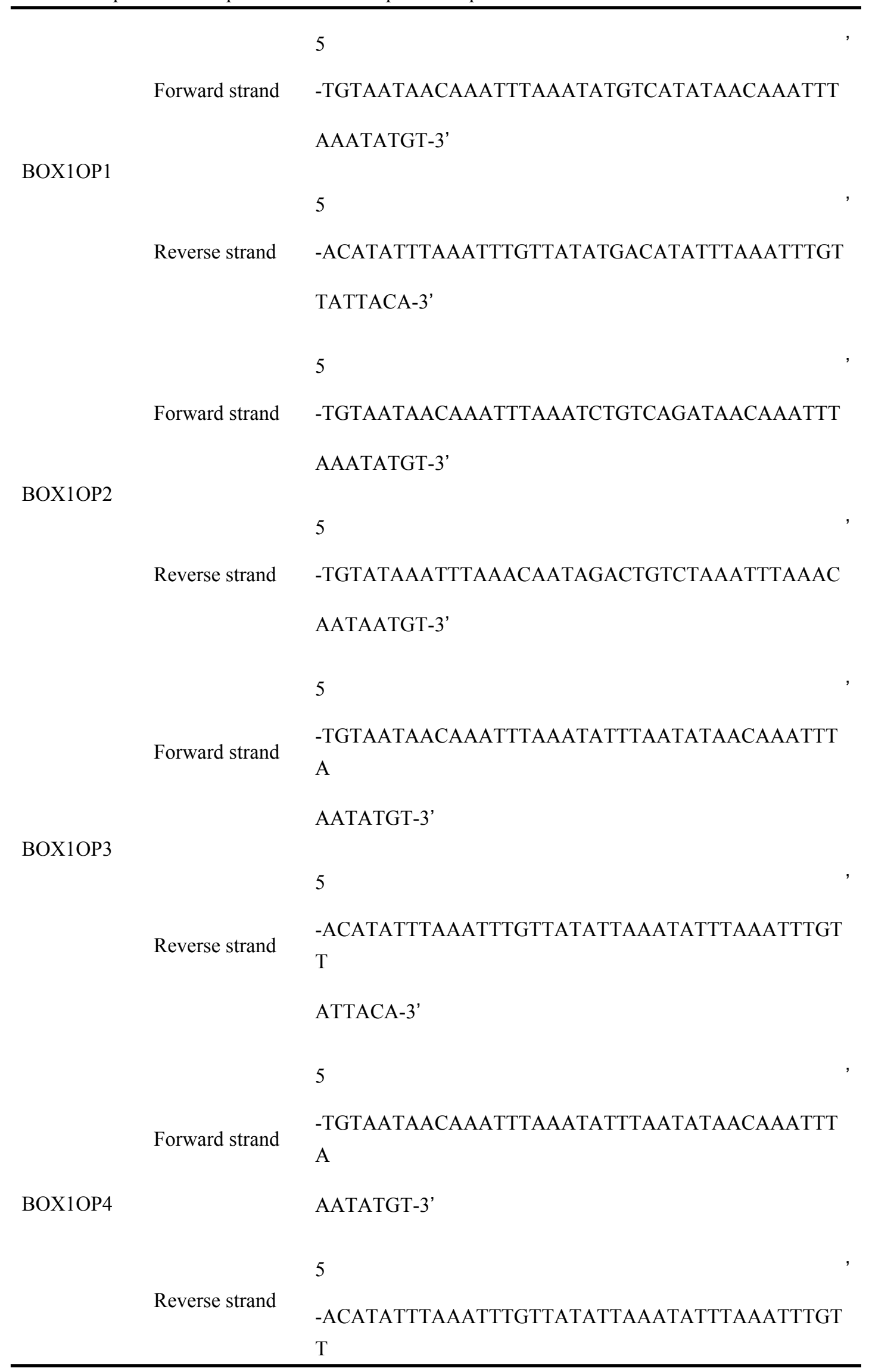




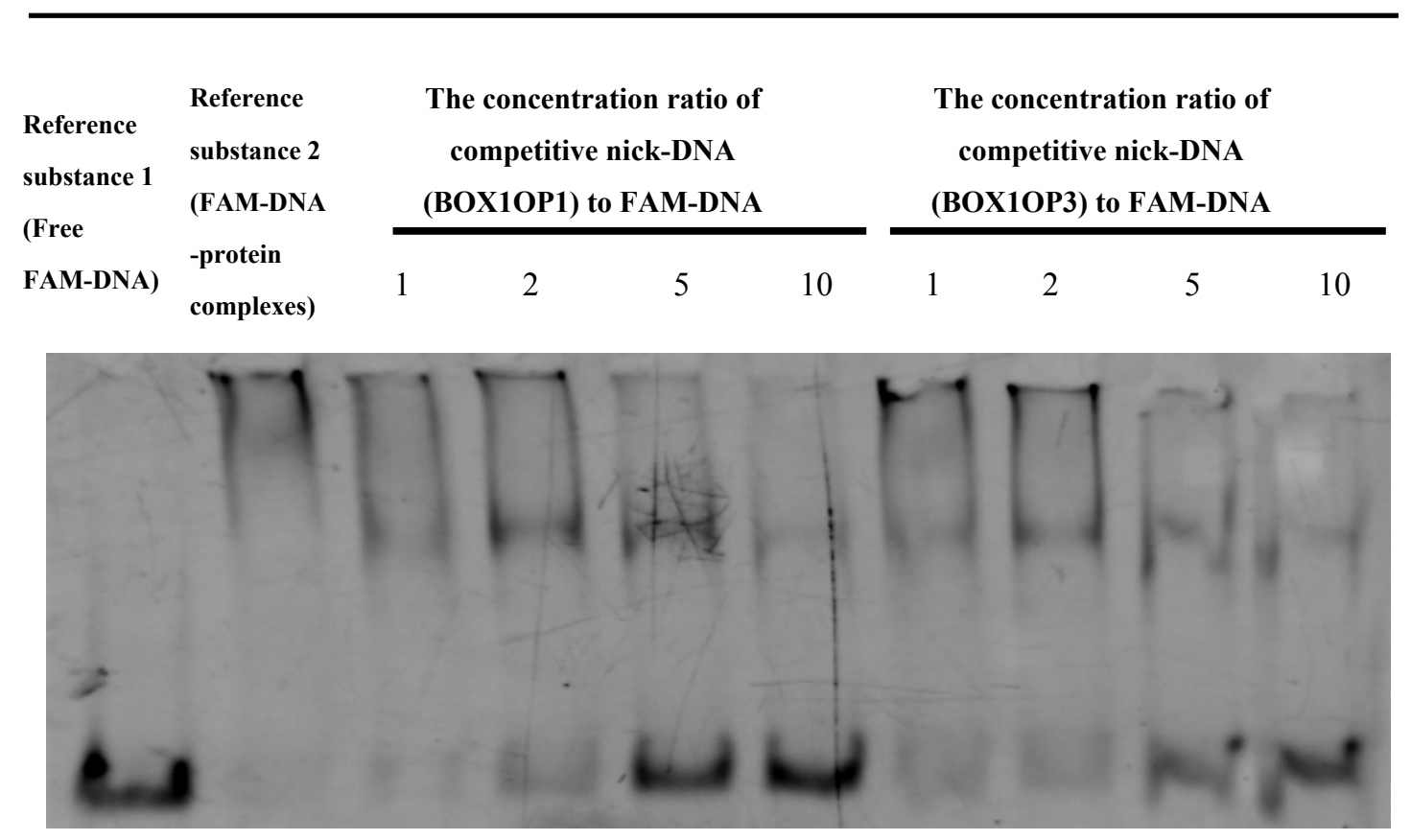

Figure 5. EMSA for detecting the protein binding ability of optimal competitive nick-DNAs with FAM-DNA.

When the ratio between added BOX1OP1 or BOX1OP3 and FAM-DNA concentration was 10, the binding bands of FAM-DNA with the protein generally were completely dissociated into free bands (Fig. 5). Both BOX1OP1 and BOX1OP3 had a strong binding affinity for the proteins; therefore, the two optimized fragments, BOX1OP1 and BOX1OP3, were used for the crystallization assay.

\subsection{Crystallization}

CbbR_7120 was crystallized separately and then coincubated with linker DNA overnight (Table 6).

Table 6. Crystallization Information

\begin{tabular}{|l|l|l|l}
\hline Linker_DNA & Conc. of Linker_DNA & Type of Pr. & Conc. of Pr. \\
\hline BOX1OP1 & $220 \mathrm{mM}$ & CbbR_7120 & $200 \mathrm{mM}$ \\
\hline BOX1OP3 & $220 \mathrm{mM}$ & CbbR_7120 & $200 \mathrm{mM}$ \\
\hline- & - & CbbR_7120 & $400 \mathrm{mM}$ \\
\hline
\end{tabular}

Microscopic observations revealed the precipitation of protein crystals under the following crystallization conditions (Fig. 6a). 
(a)

1. Kit 2H: CbbR-7120

0.1 M HEPES Sodium $\mathrm{pH} 7.5$

1.5 M Lithium sulfate monohydrate

2. Grid I 5F: CbbR-7210 with DNA (BOX1OP1) $20 \%$ PEG 6000,

$0.1 \mathrm{M}$ Critric acid $\mathrm{pH} 5.0$

3. Grid I 5G: CbbR-7210 with DNA (BOX1OP1) $20 \%$ PEG 6000 ,

$0.1 \mathrm{M}$ MES $\mathrm{pH} 6.0$ (b)
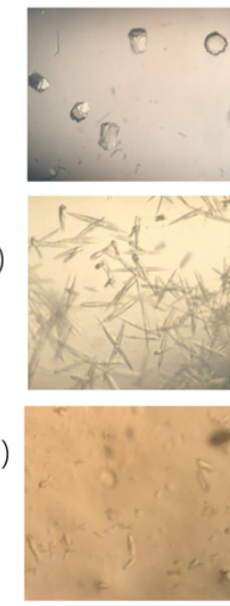

(c)

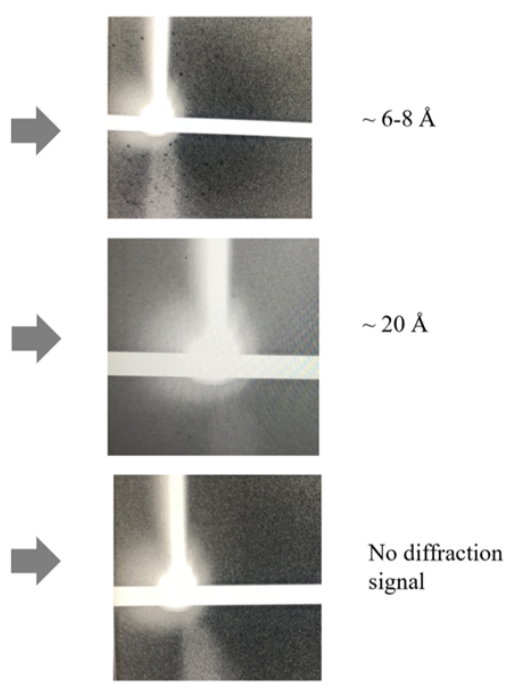

Figure 6. (a) Crystallization conditions. (b) Crystals of CbbR_7120 and CbbR_7120 with DNA. (c) $\mathrm{X}$-ray diffraction patterns from the crystals.

In this study, we obtained the optimal expression conditions of CbbR in Nostoc sp. PCC 7120. The transformed, expressed and purified CbbR protein under the above conditions had high expression and relatively high purity. Additionally, an EMSA assay was used to obtain the DNA nick fragments that were tightly bound to the DBD region of CbbR_7120. Protein crystals were obtained by crystallization of the CbbR-7120, CbbR-7120 and DNA nick complexes. We optimized and analyzed the protein crystals and further elaborated their roles and functions in the CBB cycle in subsequent assays.

\section{References}

[1] Hügler M, Sievert SM. Beyond the Calvin cycle: autotrophic carbon fixation in the ocean. Annual review of marine science. 2011 Jan 15; 3:261-89.

[2] Teich R, Zauner S, Baurain D, Brinkmann H, Petersen J. Origin and distribution of Calvin cycle fructose and sedoheptulose bisphosphatases in plantae and complex algae: a single secondary origin of complex red plastids and subsequent propagation via tertiary endosymbioses. Protist. 2007 Jul 18;158(3):263-76.

[3] Badger MR, Bek EJ. Multiple Rubisco forms in proteobacteria: their functional significance in relation to $\mathrm{CO}_{2}$ acquisition by the CBB cycle. Journal of experimental botany. 2008 May 1;59(7):1525-41.

[4] Price GD, Badger MR, Woodger FJ, Long BM. Advances in understanding the cyanobacterial $\mathrm{CO}_{2}$-concentrating-mechanism $(\mathrm{CCM})$ : functional components, $\mathrm{Ci}$ transporters, diversity, genetic regulation and prospects for engineering into plants. Journal of experimental botany. 2008 May 1;59(7):1441-61. 
[5] Terazono K, Hayashi NR, Igarashi Y. CbbR, a LysR-type transcriptional regulator from Hydrogenophilus thermoluteolus, binds two cbb promoter regions. FEMS microbiology letters. 2001 May 1;198(2):151-7.

[6] Dangel AW, Tabita FR. CbbR, the master regulator for microbial carbon dioxide fixation. Journal of bacteriology. 2015 Nov 15;197(22):3488-98.

[7] Dubbs JM, Bird TH, Bauer CE, Tabita FR. Interaction of CbbR and RegA* transcription regulators with the Rhodobacter sphaeroides cbb I promoter-operator region. Journal of Biological Chemistry. 2000 Jun 23;275(25):19224-30.

[8] Van Keulen G, Ridder AN, Dijkhuizen L, Meijer WG. Analysis of DNA binding and transcriptional activation by the LysR-type transcriptional regulator CbbR of Xanthobacter flavus. Journal of bacteriology. 2003 Feb 15;185(4):1245-52.

[9] Joshi GS, Zianni M, Bobst CE, Tabita FR. Further unraveling the regulatory twist by elucidating metabolic coinducer-mediated $\mathrm{CbbR-cbbI}$ promoter interactions in Rhodopseudomonas palustris CGA010. Journal of bacteriology. 2012 Mar 15;194(6):1350-60.

[10] Portis Jr AR, Li C, Wang D, Salvucci ME. Regulation of Rubisco activase and its interaction with Rubisco. Journal of experimental botany. 2008 May 1;59(7):1597-604.

[11] Dubbs JM, Tabita FR. Interactions of the cbbII promoter-operator region with CbbR and RegA (PrrA) regulators indicate distinct mechanisms to control expression of the two cbb operons of Rhodobacter sphaeroides. Journal of Biological Chemistry. 2003 May 2;278(18):16443-50.

[12] Van den Bergh, E R, Dijkhuizen, L, Meijer, W G. CbbR, a LysR-type transcriptional activator, is required for expression of the autotrophic $\mathrm{CO}_{2}$ fixation enzymes of Xanthobacter flavus.[J]. Journal of Bacteriology, 175(19):6097-6104.

[13] Monferrer D, Tralau T, Kertesz MA, Dix I, Solà M, Usón I. Structural studies on the full-length LysR-type regulator TsaR from Comamonas testosteroni T-2 reveal a novel open conformation of the tetrameric LTTR fold. Molecular microbiology. 2010 Mar;75(5):1199-214.

[14] Woodger FJ, Bryant DA, Price GD. Transcriptional regulation of the $\mathrm{CO}_{2}$-concentrating mechanism in a euryhaline, coastal marine cyanobacterium, Synechococcus sp. strain PCC 7002: role of NdhR/CcmR. Journal of Bacteriology. 2007 May 1;189(9):3335-47.

[15] Mahounga DM, Sun H, Jiang YL. Crystal structure of the effector-binding domain of Synechococcus elongatus $\mathrm{CmpR}$ in complex with ribulose 1, 5-bisphosphate. Acta Crystallographica Section F: Structural Biology Communications. 2018 Aug 1;74(8):506-11.

[16] Dangel AW, Luther A, Tabita FR. Amino acid residues of RegA important for interactions with the CbbR-DNA complex of Rhodobacter sphaeroides. Journal of bacteriology. 2014 Sep 1;196(17):3179-90.

[17] Omata T, Gohta S, Takahashi Y, Harano Y, Maeda SI. Involvement of a CbbR homolog in low $\mathrm{CO}_{2}$-induced activation of the bicarbonate transporter operon in cyanobacteria. Journal of bacteriology. 2001 Mar 15;183(6):1891-8.

[18] Maddocks SE, Oyston PC. Structure and function of the LysR-type transcriptional regulator (LTTR) family proteins. Microbiology. 2008 Dec 1;154(12):3609-23. 
[19] Picossi S, Flores E, Herrero A. The LysR-type transcription factor PacR is a global regulator of photosynthetic carbon assimilation in A nabaena. Environmental microbiology. 2015 Sep;17(9):3341-51.

[20] Nierzwicki-Bauer SA, Curtis SE, Haselkorn R. Cotranscription of genes encoding the small and large subunits of ribulose-1,5-bisphosphate carboxylase in the cyanobacterium Anabaena 7120. Proceedings of the National Academy of Sciences. 1984 Oct 1;81(19):5961-5. 


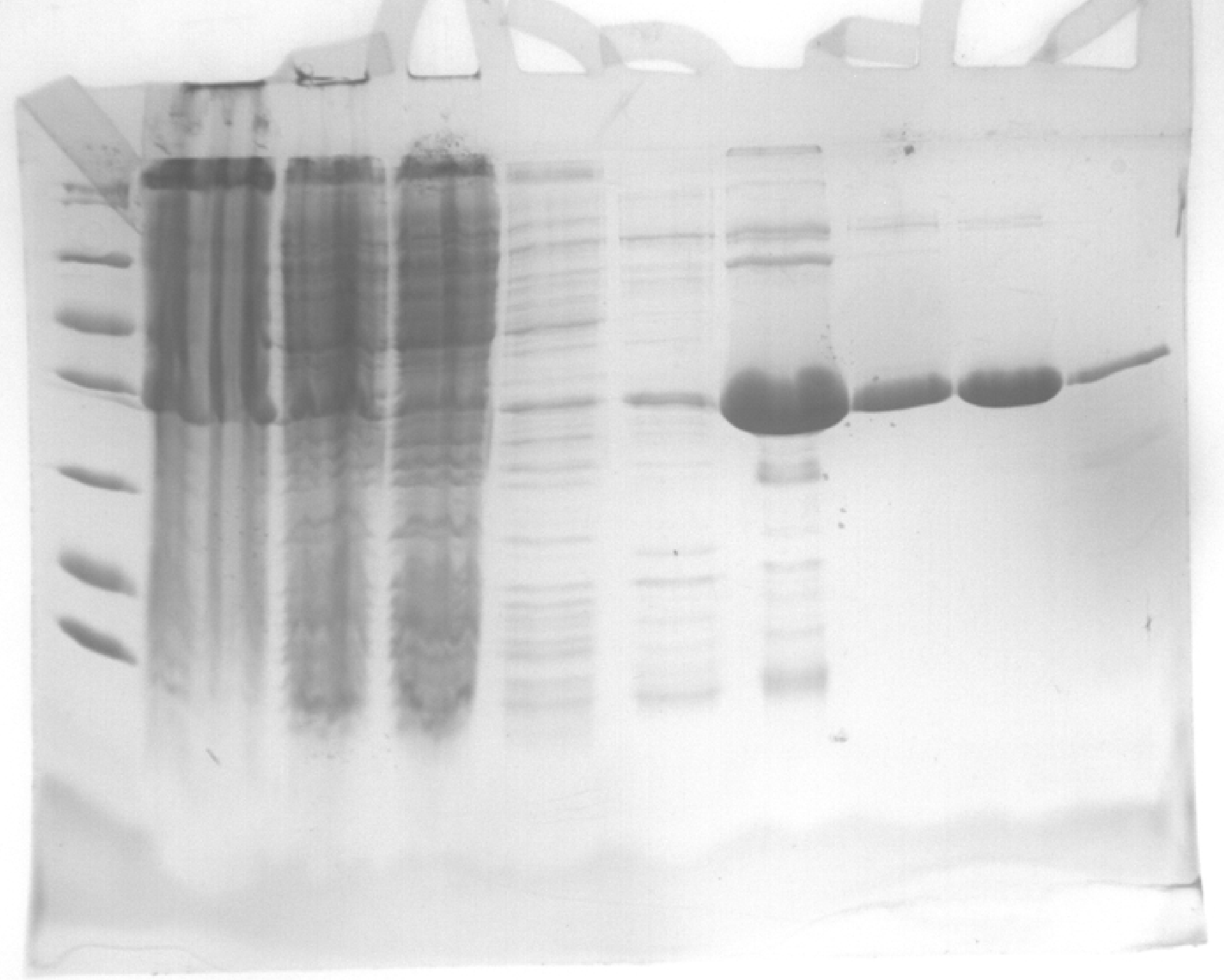




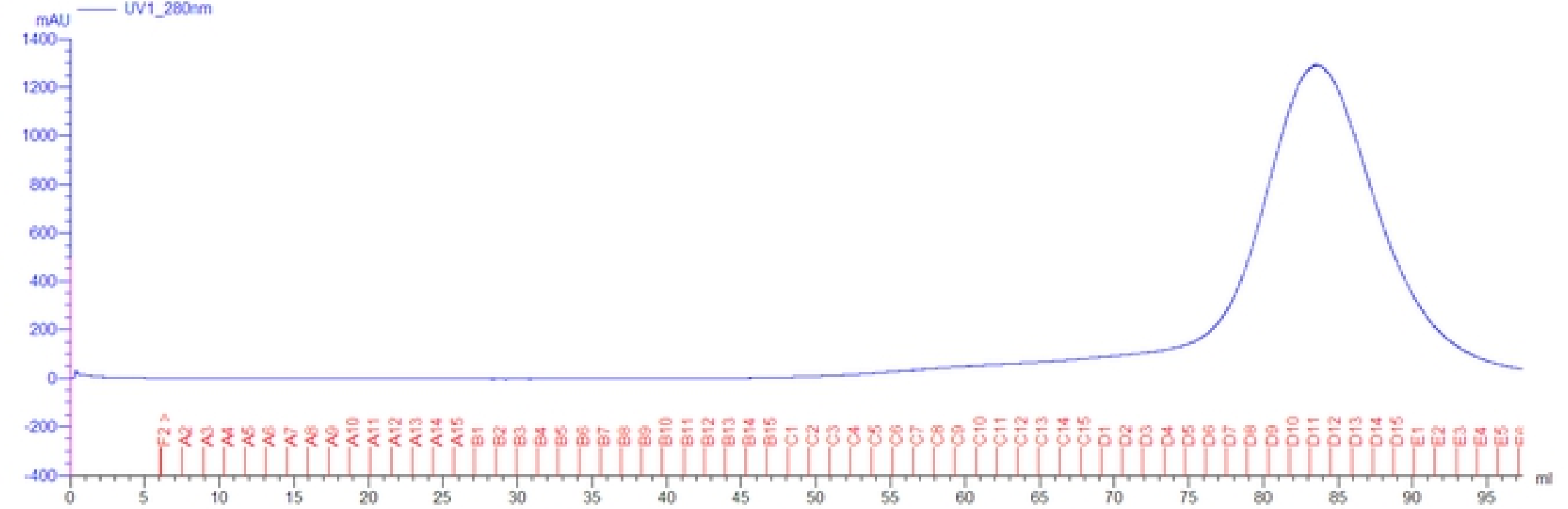







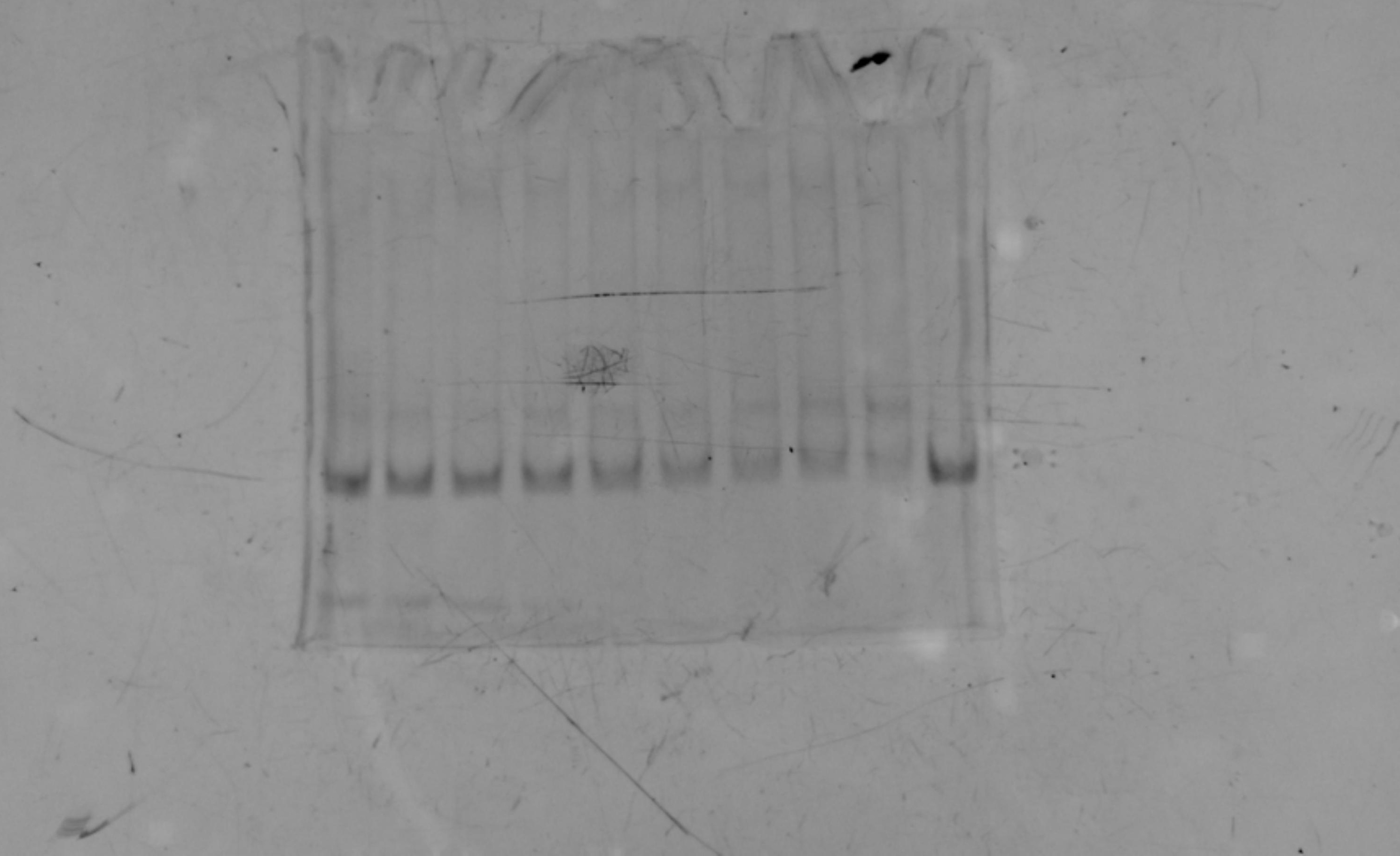





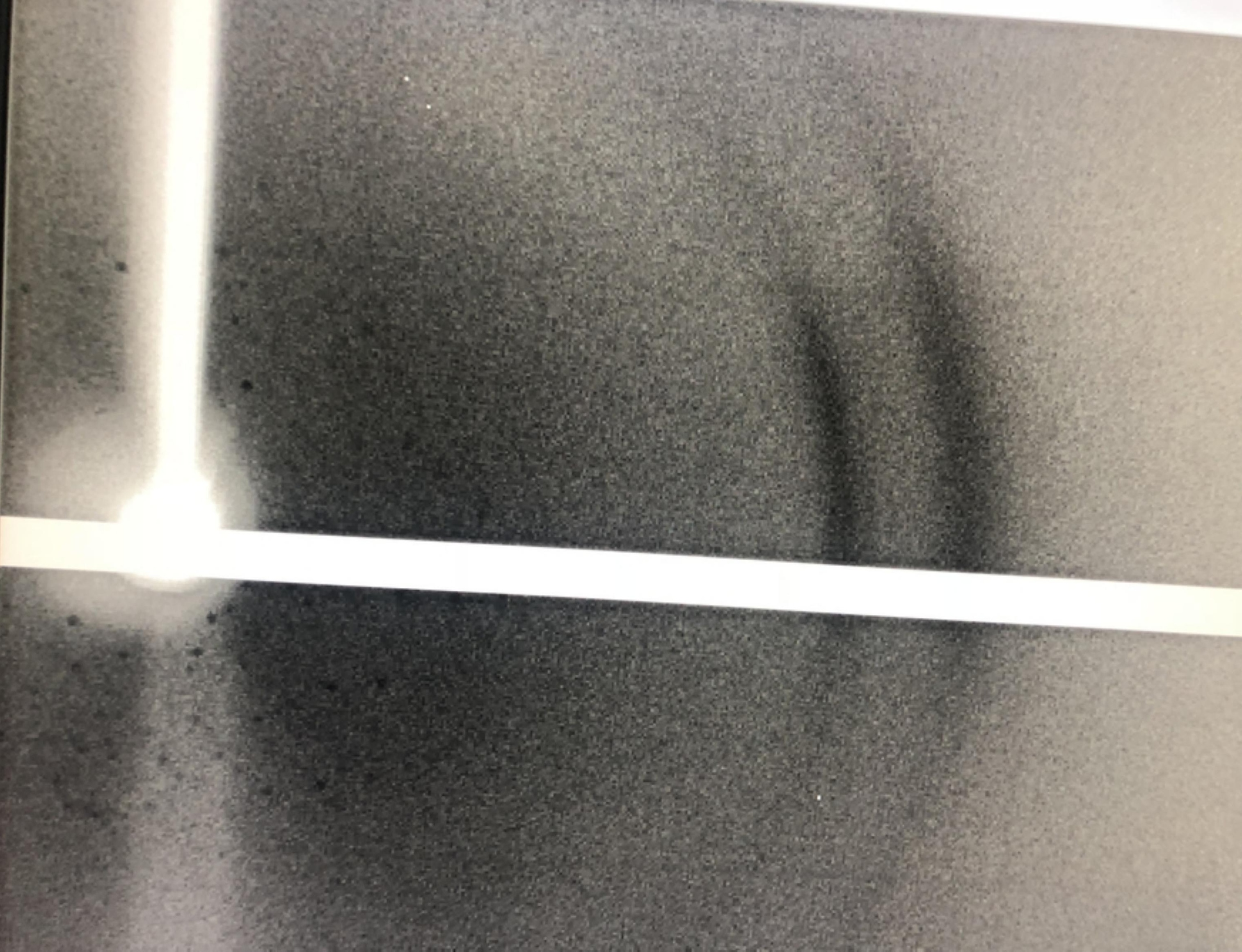




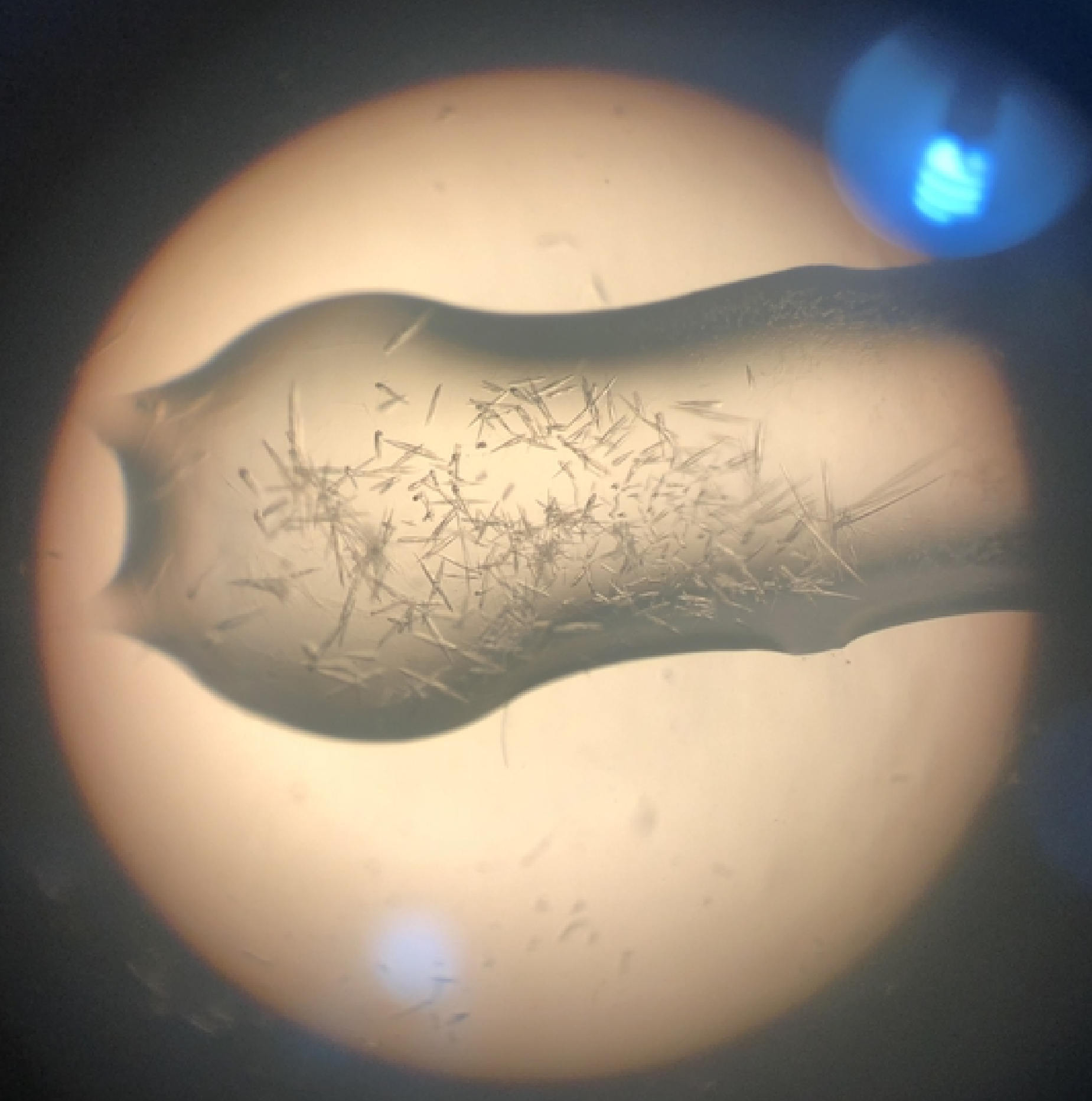




